\title{
Multidimensional Approach to Evaluation of Visegrad Countries 'competitiveness in Comparison with Austria and Germany
}

\author{
Stanickková Michaela, Melecký Lukás
}

\begin{abstract}
The paper deals with an application of Data Envelopment Analysis (DEA) method to multicriteria performance evaluation of the Visegrad Four countries (V4) in comparison with selected advanced European Union's (EU) countries - Austria and Germany. The aim of the paper is to analyse a degree of efficiency achieved in individual countries which is perceived as a reflection of the level of competitive potential in three reference years 2000, 2005 and 2010. The theoretical part of the paper is shortly devoted to the fundamental bases of competitiveness in the context of performance/productivity theory and the methodology of factor and cluster analysis (FA, CA) and DEA method. The multivariate methods, CA and FA, have been used to DEA modelling. The empirical part is aimed at measuring the degree of productivity and level of efficiency changes of evaluated countries by the specialized DEA approach - the Malmquist (Productivity) Index (MI/MPI) measuring the change of technical efficiency and the movement of the frontier in terms of evaluated countries. The final part of the paper offers a comprehensive comparison of results obtained by calculating the MI/MPI.
\end{abstract}

Key words: competitiveness, cluster analysis, DE A method, efficiency, factor analysis, performance

\section{INTRODUCTION}

European Union is a heterogeneous unit with significant disparities between its Member States and their regions. The support of cohesion and balanced regional development together with increasing level of EU competitiveness belong to the temporary EU's key development objectives. The process of European integration is thus guided by striving for two different objectives: to foster economic competitiveness and to reduce national/regional differences. Although the $\mathrm{EU}$ is one of the most developed parts of the world with high living standards, there exist huge economic, social, environmental and territorial disparities having a negative impact on the balanced development across Member States and their regions, and thus weaken EU's competitiveness in a global context. In relation to competitiveness, performance and efficiency they are complementary objectives, which determine the long-term development of states and regions. Measurement, analysis and evaluation of productivity changes, efficiency and level of competitiveness are controversial topics acquire great interest among researchers. In the EU, the process of achieving an increasing trend of performance and a higher level of competitiveness is significantly difficult by the heterogeneity of countries and regions (in many areas). The concept of competitiveness in the EU is specific regarding the inclusion of elements of European integration that goes beyond the purely economic parameters. The economy may be competitive but if the society and the environment suffer too much the country will face major difficulties, and vice versa. Therefore governments in the long run period cannot 
focus alone on the economic competitiveness of their country; instead they need an integrated approach to govern the country and focus on the broadest aspects affecting competitiveness and thus efficiency.

\section{THEORETICAL BACKGROUND OF COMPETITIVENESS IN THE CONTEXT OF PERFORMANCE AND EFFICIENCY ANALYSIS}

In recent years, the topics about measuring and evaluating of competitiveness have enjoyed economic interest. Although there is no uniform definition and understanding of competitiveness, this concept remains one of the basic standards of performance evaluation and it is also seen as a reflection of success of area (company/country/region) in a wider (international/inter-regional) comparison. Performance is also highly important for an area (company/country/region) as a whole and for the individuals involving in it. Performance comprises both a behavioral and an outcome aspect, and it is thus a multidimensional and dynamic concept as competitiveness. Despite the great relevance of performance and widespread use of this term as an outcome measure in empirical research, relatively little effort has been spent on clarifying the performance concept. In relation to competitiveness and performance, efficiency is a term that recently has come to the forefront of the scientific world. As the world struggles to accommodate the enormous growth in population and to manage the distribution of resources, to reach higher competitive potential, the effort to make things more efficient has become increasingly more relevant. Efficiency is a central issue in analyses of economic growth, effects of fiscal policies, pricing of capital assets, level of investments, technology changes and production technology, and other economic topics. In a competitive economy, therefore, the issue of efficiency, resp. dynamic efficiency, can be resolved by comparing these economic issues.

\subsection{Concept of competitiveness in the framework of performance and efficiency}

Competitiveness remains a concept that can be understood in different ways and levels despite widespread acceptance of its importance. The concept of competitiveness is distinguished at three different levels - microeconomic, macroeconomic and regional. There are some differences between these approaches as Krugman (1994) mentioned.

In original meaning the concept of competitiveness was applied only to companies and corporate strategies, this concept thus corresponds to microeconomic approach to competitiveness. Competitiveness of companies is derived from the main sources of competitiveness - the competitive advantage which companies gained through their methods of organization, production and effect on the markets in comparison to their rivals, and covers the company's ability to maintain its market position (Porter, 2003).

The need for a theoretical definition of competitiveness at macroeconomic level emerged with the development of globalization process in the world economy as a result of increased competition between countries. Despite that, growth competitiveness of the territory belongs to the main priorities of countries' economic policies and competitiveness is monitored characteristic of national economies, there is not a standardized definition and understanding of national competitiveness. One of the most common interpretations understood national competitiveness as the ability to produce 
goods and services in the country that are able to successfully face international competition, and people can enjoy a growing and sustainable living standards (Krugman, 1994).

In last few years the topic about regional competitiveness stands in the front of economic interest. Current economic fundamentals are threatened by the shifting of production activities to places with better conditions. Within governmental circles, interest has grown in the regional foundations of national competitiveness, and with developing new forms of regionally based policy interventions to help improve the competitiveness of every region and major city, and hence the national economy as a whole. In the global economy regions are increasingly becoming the drivers of the economy and regions thus play an increasingly important role in the economic development of states (Melecký, Nevima, 2011).

Nowadays competitiveness is one of the fundamental criteria for evaluating economic performance and reflects the success in the broader comparison. Organizations (companies/states/regions) need bighly performing units in order to meet their goals, to deliver the products and services they specialized in, and finally to achieve competitive advantage (Martin, 2005). Low efficiency and not achieving the goals might be experienced as dissatisfying or even as a failure. Moreover, performance - if it is recognized by others organizations - is often rewarded by benefits, e.g. better market position, higher competitive advantages, financial condition etc. Performance is a major, although not the only, prerequisite for future economic and social development. Performance management is one of the major sources of sustainable national effectiveness and a systematic understanding of the factors that affect productivity, and subsequently competitiveness, is very important.

\subsection{Evaluation of competitiveness and efficiency analysis}

Evaluation of competitiveness in terms of differences between countries and regions should be measured through complex of economic, social, environmental criteria identifying imbalance areas that cause main disparities. Currently not only quantitative but also qualitative development at national and especially regional level increase socio-economic attraction and create new opportunities that are fundamentals for subsequent overcoming disparities and increasing the competitiveness of territory.

The primary problem in creating an effective competitiveness evaluation system is establishing clear performance and efficiency standards and priorities at the beginning of the performance cycle. The early work on this problem focused on separate measures for productivity and there was a failure to combine the measurements of multiple inputs into any satisfactory measure of efficiency. These inadequate approaches included forming an average productivity for a single input (ignoring all other inputs), and constructing an index of efficiency in which a weighted average of inputs is compared with output. Responding to these inadequacies of separate indices of labour productivity, capital productivity, etc., Farrell (1957) proposed an activity analysis approach that could more adequately deal with the problem. His measures were intended to be applicable to any productive organization; in other words, "from a workshop to a whole economy" (Mohammadi, Ranaei, 2011). Farrell (1957) confined his numerical examples and discussion to single output situations, although he was able to formulate a multiple output case. Twenty years after Farrell's model, and building on those ideas, Charnes, Cooper and Rhodes in 1978, responding to the need for satisfactory procedures to assess the relative efficiencies of multi-input/multi-output production units, introduced a powerful methodology which has subsequently been titled DEA (Zhu, 2012). 
Measurement and evaluation of performance, efficiency and productivity as basis for determining the level of competitiveness is an important issue for at least two reasons. One is that in a group of units where only limited number of candidates can be selected, the performance of each must be evaluated in a fair and consistent manner. The other is that as time progresses, better performance is expected. Hence, the units with declining performance must be identified in order to make the necessary improvements. The performance of organizations (companies/countries/regions) can be evaluated in either a cross-sectional or a time-series manner, and DEA is a useful method for both types of efficiency evaluation (Mohammadi, Ranaei, 2011). DEA method is thus a convenient method for comparing national efficiency as an assumption for the competitiveness of countries (Hančlová, 2010).

\section{MULTIVARIATE METHODS OF COMPETITIVE POTENTIAL MEASUREMENT AND EFFICIENCY ANALYSIS}

The most common quantitative methods convenient for a high number of multivariate measured variables can be identified as multivariate statistical methods. Multivariate analysis is an ever-expanding set of techniques for data analysis that encompasses a wide range of possible research situation (Hair, Black, et al., 2009). Between collections of multivariate statistical methods we can include e.g. Method of main components, Factor analysis, Cluster analysis or Data envelopment analysis, which are used in the paper. Measuring the efficiency level of evaluated countries is based on procedure in following Tab. 1.

Tab. 1 - Basic scheme of efficiency measuring and evaluation. Source: Own elaboration, 2012

\section{Input data analysis \\ Pre-processing phase » Collection of indicators » Groups of indicators for input and output}

Factor analysis

Correlation » Input factors » Output factors » Set of new composite indicators » Factor description

\section{Cluster analysis}

Hierarchical cluster analysis » Ward's method » Cluster description

DEA modelling

CCR CRS input oriented model » Malmquist productivity index » Efficiency evaluation

\subsection{Fundamental background of factor analysis}

Factor analysis (FA) including the principal components and common factor analysis, is the statistical approach that can be used to analyze interrelationships among a large number of variables and to explain to explain these variables in terms of their common underlying dimensions (factors). The objective of factor analysis is to reduce the number of variables by grouping them into a smaller set of factors.

Factor analysis is a collection of methods used to examine how underlying constructs influence the responses on a number of measured variables. Factor analysis is a method for investigating whether a number of variables of interest $Y_{1}, Y_{2}, \ldots Y_{n}$, are linearly related to a smaller number of 
unobservable factors $F_{1}, F_{2}, \ldots F_{k}$. If we suggest that one measured variable Y1, is function of two underlying factors, $F_{1}$ and $F_{2}$, then it is assumed that $Y$ variable is linearly related to the two factors $F$, as follows in equation (1) (Hair, Black, et al., 2009):

$$
Y_{1}=\beta_{10}+\beta_{11} F_{1}+\beta_{12} F_{2}+e_{1} \text {. }
$$

The error terms $e_{1}$, serves to indicate that the hypothesized relationships are not exact. In the special vocabulary of factor analysis, the parameters $\beta_{i, j}$ is referred to as loadings. For example, $\beta_{12}$ is called the loading of variable $Y_{1}$ on factor $F_{2}$. There is generally a wide range of literature based on factor analysis. For example, a hands-on how-to approach can be found in Stevens (1986); more detailed technical descriptions are provided in Cooley and Lohnes (1971) or in Harman (1976).

The main applications of factor analytic techniques are (1) to reduce the number of variables and (2) to detect structure in the relationships between variables that is to classify variables. Therefore, factor analysis is applied as a data reduction or structure detection method. Factor analyses are performed by examining the pattern of correlations between the observed measures. Measures that are highly correlated (either positively or negatively) are likely influenced by the same factors, while those that are relatively uncorrelated are likely influenced by different factors. The primary objectives of an exploratory factor analysis (EFA) are to determine (1) The number of common factors influencing a set of measures and (2) The strength of the relationship between each factor and each observed measure. There are seven usual basic steps to performing EFA, used in the empirical analysis of the paper: (1) Collection of measurement variables; (2) Obtain the correlation matrix between each of variables; (3) Selection of the number of factors for inclusion; (4) Extraction of initial set of factors; (5) Rotation of factors to a final solution; (6) Interpretation of factor structure; (7) Construction of factor scores for further analysis.

\subsection{Theoretical basis of cluster analysis}

Cluster analysis (CA) is a group of multivariate method whose primary purpose is to group objects based on the characteristics they possess. Cluster analysis is a major technique for classifying a large number of information into meaningful subgroups, called clusters that are more manageable than individual datum. Cluster analysis classifies objects that are very similar to others in the cluster based on a set of selected characteristics. The resulting cluster of objects should exhibit high internal (within-cluster) homogeneity and high external (between-cluster) heterogeneity (Hair, Black, et al., 2009). Objects in a specific cluster share many characteristics, but are very dissimilar to objects, not belonging to the cluster. The aim of cluster analysis is to minimize variability within clusters and maximize variability between clusters. There is several clustering procedure how to form the groups of objects. The most popular procedures represent the bierarchical methods and non-bierarchical methods (Mooi, Sarstedt, 2011).

The hierarchical cluster analysis (agglomerative or divisive) is one of the most obvious methods. It uses the dissimilarities such as distances between objects when forming the clusters. The distance is mostly defined as Euclidean distances or the Squared Euclidean distance suitable for categorical variables, but there are many other specialized measures, e.g. for binary variables. After the determination of the distance measure, the clustering algorithm has to be selected. There are many methods available, the criteria used differ and hence different classification may be obtained for the same data. The most frequently used methods are: nearest neighbour (single 
linkage), furthest neighbour (complete linkage), average linkage with (between) groups, Ward's method, centroid method, median method. The last step of the cluster analysis is interpretation of the results. The most important is to select the cluster solution that the best represent the data sample. To define the characteristics of the cluster, it is appropriate to analyse the profile of cluster's variables.

\subsection{Theoretical background of DEA method}

The performance analysis provided by Data Envelopment Analysis (DEA) method can be used for evaluating territorial (national/regional) development efficiency with respect to the territorial (national/regional) factor endowment. DEA was first proposed and introduced by Charnes, Cooper and Rhodes in 1978. Since that time, researchers in a number of fields have quickly recognized that it is an excellent and easily used methodology for modelling operational processes for performance evaluations. DEA is based on Farrel model for measuring the effectiveness of units with one input and one output, which expanded Charnes, Cooper, Rhodes (CCR model) and Banker, Charnes, Cooper (BCC model), and advanced Slack-Based Model (SBM), Free Disposal Hull (FDH) and Free Replicability Hull (FRH) models (Cooper, Seiford, Zhu, 2004).

DEA is a relatively new "data oriented" approach for providing a relative efficiency assessment (DEA efficient) and evaluating the performance of a set of peer entities called Decision Making Units (DMUs) which convert multiple inputs into multiple outputs. DEA is thus a multi-criteria decision making method for evaluating effectiveness, efficiency and productivity of a homogenous group (DMUs). The definition of DMU is generic and flexible. DEA is convenient to determine the efficiency of DMU, which are mutually comparable - using the same inputs, producing the same outputs, but their performances are different. DMU is efficient if the observed data correspond to testing whether DMU is on the imaginary 'production possibility frontier'. All other DMU are simply inefficient. The best-practice units are used as a reference for evaluation of the other group units. The aim of this method is to decide if DMU is effective or not effective by the size and quantity of consumed resources and by the produced output (Cook, Zhu, 2008). It should be noted DEA is primarily a diagnostic tool and does not prescribe any reengineering strategies to improve performance of DMUs.

\section{APPLICATION OF MULTIVARIATE METHODS TO EFFICIENCY EVALUATION IN V4 COUNTRIES, AUSTRIA AND GERMANY}

\subsection{Fundamental basis of empirical analysis}

The aim of this paper is to measure and evaluate the efficiency level of countries within the group of Visegrad Four (V4), i.e. Czech Republic (CZ), Hungary (HU), Poland (PL) and Slovakia (SK), in comparison with selected advanced EU Member States - Austria (AT) and Germany (DE) by application of multivariate methods - factor and cluster analysis and subsequent by DEA method. The performance analysis is used for evaluating national development quality and potential (with respect to the national factors endowment). DEA method becomes a suitable tool for ranking competitive (uncompetitive) position of countries based on their efficiency. Application of DEA method is based on assumption that efficiency of V4 countries, Austria and Germany calculated by DEA method can be seen as the source of national competitiveness (competitive potential). 
Based on the above facts, it is possible to determine the initial bypothesis of the analysis. The hypothesis is based on the assumption that evaluated countries achieving best results in efficiency are countries best at converting inputs into outputs and therefore having the greatest performance and productive potential.

The efficiency analysis starts from building database of indicators that are part of a common approach of WEF and EU in the form of Country Competitiveness Index (CCI). The aim of this approach is to develop a rigorous method to benchmark national competitiveness and to identify the key factors which drive the low competitiveness performance of some countries. The reference to CCI is the well-established Global Competitiveness Index (GCI) by WEF. Eleven pillars of CCI may be grouped according to the different dimensions (input versus output aspects) of national competitiveness they describe. The terms 'inputs' and 'outputs' are meant to classify pillars into those which describe driving forces of competitiveness, also in terms of long-term potentiality, and those which are direct or indirect outcomes of a competitive society and economy. From this point of view, methodology of Country Competitiveness Index is suitable and very convenient for measuring of national competitiveness by DE A method (Annoni, Kozovska, 2010).

The indicators selected for the CCI framework are all of quantitative type (hard data) and the preferred source has been the European Statistical Office (Eurostat). Whenever information has been unavailable or inappropriate at the required territorial level, other data sources have been explored such as the World Bank, Euro barometer, the Organisation for Economic Co-operation and Development (OECD) and the European Cluster Observatory. In this paper, database analysis consists of 66 selected indicators -38 of them are inputs and 28 outputs. We do not use all indicators included in CCI because all indicators were not available for the whole period for each country, but for some indicators we found comparable indicators. The pillars and used indicators are listed in Appendix - Tab.1 and Tab.2. The reference period is set across the board for years 2000-2005-2010. We evaluate the change, individual countries achieved in its overall performance in the years 2000 , 2005 and 2010 in comparison with basis year, i.e. 2000: 2000-2005 and 2000-2010. Furthermore, we analyse productivity changes that occurred between evaluated periods, i.e. the between 2000 2005 and 2005-2010 compared to previous period, not to basis period.

For calculations of economic efficiency of V4 countries in comparison with Austria and Germany, it is used advanced DEA approach to performance evaluation known as the Malmquist (Productivity) Index (MI/MPI). Basic and advanced DEA models with multiple inputs and outputs, such as CCR input oriented model, assuming constant returns to scale (CRS), CCR output oriented model assuming CRS, BCC input oriented model assuming variable returns to scale (VRS), BCC output oriented model assuming VRS, SBM additive model not-focusing on input and output assuming CRS, SBM additive model not-focusing on input and output assuming variable returns to scale VRS, FDH input oriented model, FDH output oriented model, FRH input oriented model, FRH output oriented model, were used in previous authors' papers; see e.g. (Staníčková, Skokan, 2012).

Since the publication of Färe et al. (1994), several studies have analysed the reasons for differing performance in different countries from a frontier approach estimated through non-parametric methods. Research effort has focused on the investigation of the causes of productivity change and on its decomposition. In recent years, the Malmquist (Productivity) Index (MI/MPI) has become the standard approach in the productivity measurement over time within the nonparametric literature. The Malmquist index was introduced by Caves, Christensen and Diewert 
in 1982, whose use became generalized after Färe et al. in 1994, was published. Färe et al. (1994) defined an input-oriented productivity index as the geometric mean of the two Malmquist indices developed by Caves et al. (Färe et al., 1994).

Although it was developed in a consumer context, MI/MPI recently has enjoyed widespread use in a production context, in which multiple but cardinally measurable output replaces scalarvalued but ordinal measurable utility. In producer analysis Malmquist indexes can be used to construct indexes of input, output or productivity, as ratios of input or output distance functions. There are various methods for measuring distance functions, and the most famous one is the linear programming method. The Malmquist index allows measuring of total productivity by means of distance-functions calculation, which can be estimated through the solution of mathematical programming problems of the DEA kind.

Suppose we have a production function in time period $t$ as well as period $t+1$. The Malmquist index calculation requires two single period and two mixed period measures. The two single period measures can be obtained by using the CCR model with Constant Returns to Scale (CRS). For simplicity of the Malmquist index calculation, we present basic DEA models based on assumption of a single input and output.

Suppose each $D M U_{j}(j=1,2, \ldots, n)$ produces a vector of output $y_{j}^{t}=\left(y_{1 j}^{t}, \ldots, y_{s j}^{t}\right)$ by using a vector of inputs $x_{j}^{t}=\left(x_{1 j}, \ldots, x_{m j}\right)$ at each time period $t, t=1, \ldots$, T. From $t$ to $t+1, D M U_{0}$ 's efficiency may change or (and) the frontier may shift. Malmquist productivity index is calculated via (2) comparing $x_{0}{ }^{t}$ to the frontier at time t, i.e., calculating the coefficient of efficiency of $D M U_{0}$, i.e. $\theta_{0}{ }^{t}$, depending on the values of input $x$ and output $y$ in time $t$, i.e. $\theta_{0}^{t}\left(x_{0}^{t}, y_{0}^{t}\right)$ in the following inputoriented CCR CRS envelopment DEA model (2) (Zhu, 2012):

$$
\theta_{0}^{t}\left(x_{0}^{t}, y_{0}^{t}\right)=\min \theta_{0} \text {, }
$$

subject to

$$
\begin{gathered}
\sum_{j=1}^{n} \lambda_{j} x_{j}^{t} \leq \theta_{0} x_{0}^{t}, \\
\sum_{j=1}^{n} \lambda_{j} y_{j}^{t} \geq y_{0}^{t}, \\
\lambda_{j} \geq 0, j=1, \ldots, n,
\end{gathered}
$$

where $x_{0}{ }^{t}=\left(x_{10}{ }^{t}, \ldots, x_{m 0^{t}}\right)$ and $y_{0}{ }^{t}=\left(y_{10}{ }^{t}, \ldots, y_{s 0}{ }^{t}\right)$ are input and output vectors of DMU0 among others, and $\lambda$ is vector of weights assigned to individual $D M U_{0}$. The variable $\theta_{0}^{t}$ can also be interpreted as a needed rate of inputs reduction to achieve efficient frontier.

Malmquist productivity index is further calculated via (3) comparing $x_{0}^{(t+1)}$ to the frontier at time $t+1$, i.e., calculating $\theta_{0}{ }^{t+1}\left(x_{0}{ }^{t+1}, y_{0}{ }^{t+1}\right)$ in the following input-oriented CCR CRS envelopment DEA model (3) (Zhu, 2012):

$$
\theta_{0}^{t+1}\left(x_{0}^{t+1}, y_{0}^{t+1}\right)=\min \theta_{0}
$$

subject to

$$
\begin{aligned}
& \sum_{j=1}^{n} \lambda_{j} x_{j}^{t+1} \leq \theta_{0} x_{0}^{t+1}, \\
& \sum_{j=1}^{n} \lambda_{j} x_{j}^{t+1} \geq y_{0}^{t+1}, \\
& \lambda_{j} \geq 0, j=1, \ldots, n .
\end{aligned}
$$

Malmquist productivity index is further calculated via (4) comparing $x_{0}{ }^{t}$ to the frontier at time $t+1$, i.e., calculating $\theta_{0}^{t+1}\left(x_{0}^{t}, y_{0}^{t}\right)$ via the following linear program equation (4) (Zhu, 2012): 
subject to

$$
\theta_{0}^{t+1}\left(x_{0}^{t}, y_{0}^{t}\right)=\min \dot{\theta}_{0}^{-}
$$

$$
\begin{aligned}
& \sum_{j=1}^{n} \lambda_{j} x_{j}^{t+1} \leq \theta_{0} x_{0}^{t}, \\
& \sum_{j=1}^{n} \lambda_{j} x_{j}^{t+1} \geq y_{0}^{t}, \\
& \lambda_{j} \geq 0, j=1, \ldots, n .
\end{aligned}
$$

Malmquist productivity index is further calculated via (5) comparing $x_{0}^{t+1}$ to the frontier at time $t$, i.e., calculating $\theta_{0}{ }^{t}\left(x_{0}{ }^{t+1}, y_{0}{ }^{t+1}\right)$ via the following linear program equation (5) (Zhu, 2012):

$$
\theta_{0}^{t}\left(x_{0}^{t+1}, y_{0}^{t+1}\right)=\min \theta_{0},
$$

subject to

$$
\begin{gathered}
\sum_{j=1}^{n} \lambda_{j} x_{j}^{t} \leq \theta_{0} x_{0}^{t+1}, \\
\sum_{j=1}^{n} \lambda_{j} x_{j}^{t} \geq y_{0}^{t+1}, \\
\lambda_{j} \geq 0, j=1, \ldots, n .
\end{gathered}
$$

The Malmquist index $M_{0}$ measuring the efficiency change of production units between successive periods $t$ and $t+1$, is formulated in the following form (6) (Zhu, 2012):

$$
M_{0}\left(x^{t+1}, y^{t+1}, x^{t}, y^{t}\right)=E_{0} \cdot P_{0},
$$

where $E_{0}$ is change in the relative efficiency of $D M U_{0}$ in relation to other units (i.e. due to the production possibility frontier) between time periods $\mathrm{t}$ and $t+1 ; P_{0}$ describes the change in the production possibility frontier as a result of the technology development between time periods $t$ and $t+1$. The following modification of $M_{0}$ (equation (7)) makes it possible to measure the change of technical efficiency and the movement of the frontier in terms of a specific DMU0 (Zhu, 2012):

$$
M_{0}=\frac{\theta_{0}^{t}\left(x_{0}^{t}, y_{0}^{t}\right)}{\theta_{0}^{t+1}\left(x_{0}^{t+1}, y_{0}^{t+1}\right)}\left[\frac{\theta_{0}^{t+1}\left(x_{0}^{t+1}, y_{0}^{t+1}\right)}{\theta_{0}^{t}\left(x_{0}^{t+1}, y_{0}^{t+1}\right)} \cdot \frac{\theta_{0}^{t+1}\left(x_{0}^{t}, y_{0}^{t}\right)}{\theta_{0}^{t}\left(x_{0}^{t}, y_{0}^{t}\right)}\right]^{1 / 2} .
$$

The first component $P_{0}$ on the right hand side measures the magnitude of technical efficiency change (TEC) between time periods $t$ and $t+1$. Obviously the second component $E_{0}$ on the left hand indicating that technical efficiency improves remains or declines. The second terms measures the shift in the possibility frontier, i.e. technology frontier shift (FS), between time period's $t$ and $t+1$. Efficiency and productivity declines if $E_{0}$ and $P_{0}>1$, remains unchanged if $E_{0}$ and $P_{0}=1$ and improves if $E_{0}$ and $P_{0}<1$. In Tab. 2 characteristics of MI/MPI and efficiency change are shown.

Tab. 2 - Characteristics and trends of the Malmquist index and efficiency change. Source: Own elaboration, 2012

\begin{tabular}{|c|c|}
\hline Malmquist Index & Productivity \\
\hline$>1$ & Declining \\
\hline$=1$ & Unchanging \\
\hline$<1$ & Improving \\
\hline Efficiency Change & Technical Efficiency \\
\hline$<1$ & Improving \\
\hline$=1$ & Unchanging \\
\hline$>1$ & Declining \\
\hline
\end{tabular}


Based on the above facts, we can determine the total productivity change in a successive period of time with the following equations (8) and (9):

$$
\begin{gathered}
\text { Productivity change }=\text { Technical efficiency change } \bullet \text { Technological changes, } \\
\text { resp. MI/MPI }=\text { TEC } \bullet \text { FS. }
\end{gathered}
$$

If MI/MPI on the basis of minimization of production factors was less than one, it indicates productivity improvement, on the other hand, if on the basis of maximization of production factors, the index or any of its elements were less than one, it signifies productivity getting better, while if the index is bigger than one, it indicates productivity decrease (Zhu, 2012).

For solution of factor analysis and cluster analysis statistical package SPSS - IBM SPSS Statistics - Version 20 is used in the paper. For solution of DE $A$ models software tools based on solving linear programming problems are used, e.g. Solver in MS Excel, such as the DEA Frontier (Cooper, Seiford, Zhu, 2004; Cook, Zhu, 2008), this is used in the paper.

\subsection{Measurement of competitiveness' factors by factor analysis}

For utilization of above mentioned sources, set of 66 variables was compiled. In order to ensure comparability between different countries, all variables have to be gelatinized, and these variables thus entered into analysis. Firstly, it was necessary to obtain the correlation matrix between each of our variables and exclude variables do not meet specific requirements placed on input data in using of factor analysis. In process of data pre-processing is necessary to make their standardization (normalization), thus to unify their standards. The most commonly used method of standardization is to transform data into Z-scores. Unlike the original data matrix, $Z$ score matrix is a matrix of zero averages and unit standard deviations of all variables, which is ideal for processing by factor analysis method. Based on used data standardization method, Pearson's correlation coefficient was chosen as a measure of correlation. The ideal would be case in which correlation degree of variables do not fall below 0.3 . Like would not fall below 0.3 , correlation coefficients should appropriate variables or vice versa exceed 0.9. On basis of defined conditions, database consists of 38 indicators - 23 input and 15 output indicators, thus 15 variables for inputs and 13 variables for outputs were excluded. Database and excluded variables (illustrated by crossed font) are shown in Tab.1 and Tab.2 in Appendix.

After a relatively lengthy and complex process of variables selection, the core of factor analysis follows. Statistical package SPSS (in our case IBM SPSS Statistics - Version 20) provides a wide range of factor extraction methods. In this paper we have chosen specifically modified method of principal components because of higher number of variables. By its application to input set of variables, an estimate of the factor/component matrix (often called also as a matrix of factor loads) was provided. Content of matrix of factor loads are values of correlation coefficients between individual variables and now firmly specified number of factors. This number has been predefined in input parameters by determining the value of own number to a value greater than 1.0. Own number (eigenvalue) of a particular factor indicates the amount of total variability explained by just this factor. Very frequently criterion for finding the optimal number of factors, the percentage of total variance explained collectively by selected factors, is used. For an imaginary boundary of quality solution is widely accepted $70 \%$ of explained variability. In our case, five dominating factors for inputs explained $100 \%$ of total variability in years 2000, 2005 and 
2010 , which can be considered as very satisfactory result. In the case of outputs, four dominating factors explained 95,168\% of total variability in year 2000, 98,558\% of total variability in year 2005 and $94,188 \%$ of total variability in year 2010 , which can be considered also as very satisfactory results. These results are illustrated in Appendix - in Tab.3, 4, 5, 6, 7 and 8.

The optimal number of factors is already known, their interpretation still proceed not. One of yet unnamed conditions is that each factor has influence the most of variables, while each of variables, if it is possible, and should depend on the fewest number of factors. Further step is to rotate of factors or factorial axes, which task is just to maximize the load of each variable in one of the extracted factors, while her loads under other factors are substantially minimized. In the paper we used Varimax method of rotation, which rotates the coordinate axes in the direction of maximum variance. The matrix of factor loads, rotated just by this method, Tab.3, 4, 5, 6, 7 and 8 in Appendix offer. These tables also clearly show that target of rotation was almost completely fulfilled. Only a few variables are now characterized by high loads in more than one factor and the total structure of factor matrix is considerably simplified. For interpretation, those variables were identified as relevant, factor loadings exceeded the 0.4. This frontier was marked as convenient by Stevens (Stevens, 1986). Jurisdiction of inputs and outputs to relevant factors is illustrated by gray colour in Tab. 3, 4, 5, 6, 7 and 8 in Appendix. Based on results of correlation and factor analysis, we could proceed to cluster analysis and DEA method. Indicators for inputs and outputs, depending on their level of significance for competitiveness of evaluated countries, these indicators were divided by results of factor analysis in 2000, 2005 and 2010.

\subsection{Application of cluster analysis in the case of national disparities}

For the final matrix to cluster analysis, it was selected 38 indicators that represent the most frequently indicators of economic, social and environmental factors related to competitiveness in CCI - initial number of indicators was decreased after correlation and (based on result of factor analysis) we use optimal number of indicators at a minimum loss of information contained in original CCI. CA is used for defining clusters of countries based on the value of the individual factors. The object is sorted into groups, or clusters, so that the degree of association is strong between members of the same cluster and weak between members of different clusters. The task of clustering is then to divide the set of objects into the disjunctive clusters. To determine the optimum solution, in the paper is used the most common approach - method of hierarchical cluster analysis and the clustering algorithm is Ward's method applying Squared Euclidean Distance as the distance or similarity measure. It helps to obtain the optimum number of clusters we should work with. The next step is to rerun the hierarchical cluster analysis with this selected number of clusters, which enables us to allocate every case in our sample to a particular cluster.

The first step of CA is to select the criterion of similarity (dissimilarity) of the objects. As a measure of dissimilarity was selected the Squared Euclidean Distance and it is basis of the Ward's method. On the basis of the Proximity Matrix in Tab.9, 11 and 13 in Appendix, the highest differences in the year 2000 exist between Germany and Poland (124,983). The lowest distance is recorded between Austria and Czech Republic (47,029). In the years 2005 and 2010 are results very similar; the highest differences are again between Germany and Poland (124,292 in 2005 and 132,187 in 2010). The lowest distances are again between Austria and Czech Republic (50,162 in 2005 and 55,283 in 2010). 
The column "Coefficients" in Tab.10, 12 and 14 in Appendix, helps us to decide how many clusters are optimal for representation of the data. In this case, the cluster formation should be stop when the increase in the Coefficients is large. In this case, the best interpretation of data ensures fourcluster solution in the year 2000, as well as in the years 2005 and 2010. The number of clusters has been set, based on previous analysis, thus at 4 . The chosen algorithms allocated based on given factors the given country (object) into a certain segment. Cluster I represents only the Czech Republic, it is $16,66 \%$ of total objects. Cluster I is characterized by higher economic efficiency and performance than Cluster II achieves. The separation of this cluster from Cluster II including Hungary, Slovakia and Poland (representing $50 \%$ of total objects), implies the visible differences between V4 countries. Cluster II is characterized with the lowest level of macroeconomic indicators and the lowest level of performance. Cluster III represents only Germany (it is 16, $66 \%$ of total objects) and it is characterized by a very good economic prosperity. Cluster IV is created by Austria (representing 16, $66 \%$ of total objects) and it is distinguished by the high level of efficiency and performance trend which is characterized by the highest value of macroeconomic indicators in comparison with the other three analysed clusters. The significant disparities can be noticed between Germany and Austria on the one side and Visegrad Four countries on the other side. In the years 2005 and 2010, the structure of the four-cluster solution is identical to the clusters in the year 2000 .

\subsection{Evaluation of national efficiency by DEA method}

According to the use of the minimization-based Malmquist productivity index in this paper, therefore, if it was equal to 1 , signifies no change in efficiency and performance, if bigger than 1 it shows efficiency decline and performance getting worse, and in the case it is less than 1 it signifies efficiency getting better and performance advancement. The amount of total productivity elements and efficiency changes of all evaluated countries in years 2005 and 2010 in comparison with basic year 2000 is shown in Tab. 3. In Tab. 3 is also illustrated the productivity change occurred between evaluated periods, i.e. the between 2000-2005 and 2005-2010 compared to previous period, not to basis period. Considering the information in Tab. 3, all evaluated countries have the total efficiency and productivity decrease through the whole period because the level of MI/MPI is higher than 1 (except Austria's increase in period 2000-2005). By analysing the elements of evaluated countries' MI/MPI, we can see that technical efficiency change (TEC) equals 1 and meaning no change. The shift in the possibility frontier (FS) is higher than 1 (increasing trend), thus countries delaying the possibility frontier (except in Austria in period 2000-2005, there is opposite trend).

The worst efficiency level and performance trend was produced by Hungary because its total productivity was the lowest through the whole time period; Hungary has placed at last - sixth position. But Hungary's MI/MPI was decreasing across time periods, thus illustrating positive trend. Hungary's TEC change equals 1 and meaning no change. Hungary's FS is higher than one (but has a decreasing trend), so Hungary gradually slow approximates the possibility frontier. The worst level of efficiency and thus productivity growth was recognized also in Slovakia which illustrated the worst performance change and productivity trend and Slovakia thus has placed at fifth position. Through analysing the elements of Slovakia's MI/MPI it is clear that its TEC equals 1 so no change. The shift in the possibility frontier is higher than 1 (and has an increasing trend), 
Slovakia delaying the possibility frontier. In the case of Slovakia is clear the highest deterioration in efficiency in 2010 compared to 2000.

Czech Republic and Poland have recognized similar values of MI/MPI. Poland has illustrated slight deterioration in efficiency and performance during reference period and it has placed at fourth position. Poland's TEC equals 1 so no change. The shift in the possibility frontier is higher than 1 (and has an increasing trend), Poland thus delaying the possibility frontier. Czech Republic has recognized slight improvement in performance during reference period, and thus has placed at third position. Czech Republic has illustrated the best results of all V4 countries. TEC of Czech Republic equals 1 so no change. The shift in the possibility frontier is higher than 1 (and has a decreasing trend), Czech Republic thus very slowly approximates the possibility frontier and has the best efficiency level of all V4 countries.

Germany and Austria have also illustrated very similar values of MI/MPI. Germany has recognized very balanced trend in efficiency trend and performance development across reference period and it has placed at second place. Germany's TEC equals 1 so no change. The shift in the possibility frontier is higher than 1 (and has a decreasing trend), Germany thus approximates the possibility frontier very slowly, resp. moving more or less the same level. Austria has illustrated the best efficiency level and performance trend of all evaluated countries and thus Austria is placed at first position. Austria's TEC change equals 1 and meaning no change. Austria's FS is higher than 1 (and has an increasing trend), Austria thus delaying the possibility frontier. Compared Austria and Germany in 2000 and 2010, it is necessary to note, that Germany has recognized lower level of MI/MPI than Austria. Austria has thus illustrated significant decrease of productivity in this period, because it is only one country which has MI/MPI below 1 (in period 2000 and 2005) in the whole reference period.

Tab. 3 - Overall Productivity of Countries Based on Malmquist Index in 2000-2005-2010.

Source: Own calculation and elaboration, 2012

\begin{tabular}{|c|c|c|c|c|c|c|c|c|c|c|}
\hline \multicolumn{2}{|c|}{ Country/Time } & \multicolumn{3}{|c|}{ 1. Period 2000-2005 } & \multicolumn{3}{|c|}{ 2. Period 2005-2010 } & \multicolumn{3}{|c|}{ 3. Period 2000-2010 } \\
\hline No. & Country & $\begin{array}{c}\text { IO } \\
\text { CCR } \\
\text { CRS } \\
\text { MI* }\end{array}$ & TEC & FS & $\begin{array}{c}\mathrm{IO} \\
\mathrm{CCR} \\
\mathrm{CRS} \\
\mathrm{MI}^{*}\end{array}$ & TEC & FS & $\begin{array}{c}\mathrm{IO} \\
\mathrm{CCR} \\
\mathrm{CRS} \\
\mathrm{MI}^{*}\end{array}$ & TEC & FS \\
\hline 1 & AT0 & 0,93944 & 1,00 & 0,93944 & 1,44783 & 1,00 & 1,44783 & 1,56376 & 1,00 & 1,56376 \\
\hline 2 & $\mathrm{CZO}$ & 2,40284 & 1,00 & 2,40284 & 2,14987 & 1,00 & 2,14987 & 2,17382 & 1,00 & 2,17382 \\
\hline 3 & DE0 & 1,41060 & 1,00 & 1,41060 & 1,29947 & 1,00 & 1,29947 & 1,44304 & 1,00 & 1,44304 \\
\hline 4 & HU0 & 6,84979 & 1,00 & 6,84979 & 2,28662 & 1,00 & 2,28662 & 5,05474 & 1,00 & 5,05474 \\
\hline 5 & PL0 & 2,46138 & 1,00 & 2,46138 & 1,72731 & 1,00 & 1,72731 & 2,89633 & 1,00 & 2,89633 \\
\hline 6 & SK0 & 1,09512 & 1,00 & 1,09512 & 3,74183 & 1,00 & 3,74183 & 3,16362 & 1,00 & 3,16362 \\
\hline
\end{tabular}

Note: * IO CCR CRS MI = Malmquist Index of Input Oriented CCR Model with CRS

These facts indicate that all V4 countries, Austria and Germany have faced a noticeable efficiency deceleration and performance decline during reference period 2000-2005-2010. Slight improvement in overall efficiency was illustrated in most evaluated countries between period 2005 and 
2010 (except Austria and Slovakia). Prevailing deteriorating results in efficiency and decline in performance is especially apparent in comparing years 2000 and 2010, which corresponds to the real facts, because all countries to cope with consequences of the economic crisis. Based on analysis' results it is possible to state, there is significant differences in efficiency trend between Germany and Austria on the one side and Visegrad Four countries on the other side.

\section{CONCLUSION}

Competitiveness, performance and efficiency are complementary objectives, which determine the long-term development of countries. These are also concepts that cannot be avoided in economic theory and practice. Evaluation of competitiveness, performance and efficiency can be performed only if we use existing concept of these terms or selected mainstream. Because of the fact that there is no mainstream in competitiveness, performance and efficiency evaluation, there is space for alternative approach in this area. It is necessary to note that using different approaches to evaluation generate different results. This is logical and predictable. It cannot be expected that different approaches lead to identical conclusions about the level of competitiveness, performance and efficiency. Many methods and approaches to competitiveness, performance and efficiency evaluation are (to a certain extent) incomparable, and therefore their results must be taken into account individually. A certain degree of individual assessment should therefore apply in terms of concrete results (and order) of individual V4 countries in comparison with Austria and Germany.

Based on FA, CA and DEA analysis has been found out that in evaluated countries there is a distinct gap between economic and social standards, so differences still remain. Measuring the Malmquist index on the basis of the DEA method has been used in this paper to analyze and evaluate efficiency of individual V4 countries, Austria and Germany in period 2000-2005-2010. Regarding the findings and the analysis each country can decide whether it had a level of efficiency and productivity trend increase during the time period, or not. By having this information and dividing efficiency and subsequent productivity into its elements, the basic trend in efficiency level and productivity trend whether it be increase or decrease is observed. According to the Malmquist index results, it is necessary to note that in all evaluated countries was mostly achieved noticeable efficiency and productivity decreases and thus performance deteriorating during reference period. Development in V4 countries has a trend towards advanced Austria and Germany. Most countries experienced decline in their performance (outputs decline as a result of declines in inputs) as a result of economic crisis. The recent economic crisis has seriously threatened the achievement of sustainable development in the field of competitiveness. The crisis has underscored importance of competitiveness, supporting economic environment to enable national economies to better absorb shocks and ensure solid performance going into the future.

\section{Acknowledgement}

This paper was created under SGS project (SP2012/153) of Faculty of Economics, VŠB-Technical University of Ostrava. 


\section{References}

1. Annoni, P. \& Kozovska, K. (2010). EU Regional Competitiveness Index 2010. Luxembourg: Publication Office of the European Union.

2. Cook, W. D. \& Zhu, J. (2008). Data Envelopment Analysis: Modelling Operational Processes and Measuring Productivity. Boston: Kluwer Academic Publishers.

3. Cooley, W.W. \& Lohnes, P.R. (1971). Multivariate Data Analysis. New York: John Wiley \& Sons, Inc.

4. Cooper, W. W. \& Seiford, L. M. \& Zhu, J. (2004). Data Envelopment Analysis: History, Models and Interpretations. Boston: Kluwer Academic Publishers. http://dx.doi.org/10.1007/978-14419-6151-8_1

5. Färe, R. et al. (1994). Production Frontiers. Cambridge: University Press.

6. Farrell, M.J. (1957). The Measurement of productivity efficiency. Journal of the Royal Statistical Society, 120 (3), 253-290. http://dx.doi.org/10.2307/2343100

7. Hair, J. F. \& Black, W.C. et al. (2009). Multivariate Data Analysis. New Jersey: Prentice Hall.

8. Hančlová, J. et al. (2010). Makroekonomické modelování české ekonomiky a vybraných ekonomike EU. Ostrava: VŠB-TU Ostrava.

9. Harman, H. H. (1976). Modern factor analysis, third edition. Chicago: University of Chicago Press.

10. Mooi, E. \& Sarstedt, M. (2011). A Concise Guide to Market Research. The Process, Data, and Methods Using IBM SPSS Statistics. Heidelberg: Springer.

11. Krugman, P. (1994). Competitiveness: A Dangerous Obsession. Foreign Affairs, 73 (2), 28 44. http://dx.doi.org/10.2307/20045917

12. Martin, R. (2005). Thinking about Regional Competitiveness: Critical Issue. Retrieved September 17, 2011 from http://www.intelligenceeastmidlands.org.uk/uploads/documents/89137/ RonMartinpaper1.pdf.

13. Melecký, L. \& Nevima, J. (2011). Application of econometric panel data model for regional competitiveness evaluation of selected EU 15 countries. Journal of Competitiveness, 3 (4), 23 38.

14. Mohammadi, A. \& Ranaei, H. (2011). The Application of DEA based Malmquist Productivity Index in Organizational Performance Analysis. International Research Journal of Finance and Economics, 62 (6), 68-76.

15. Porter, M. E. (2003). The Economic Performance of Regions. Regional Studies, 37 (6/7), 549578. http://dx.doi.org/10.1080/0034340032000108688

16. Staníčková, M. \& Skokan, K. (2012). Evaluation of the EU Member States Efficiency by Data Envelopment Analysis Method. International Journal of Mathematical Models and Methods in Applied Sciences, 6 (2), 349-357.

17. Stevens, J. (1986). Applied multivariate statistics for the social sciences. New Jersey: Lawrence Erlbaum Associates.

18. Zhu, J. (2012). Manual DE A Frontier-DEA Add-In for Microsoft Excel. Retrieved June 10, 2012 from http://www.deafrontier.net/. 


\section{Contact information}

Ing. Michaela Stanickeová

$V \grave{S} B$ - Technical University of Ostrava, Faculty of Economics, Department of European Integration Sokolská trída 33, 70121 Ostrava

Email:michaela.stanickova@vsb.cz.

Ing. Lukáśs Melecký

$V S ̌ B$ - Technical University of Ostrava, Faculty of Economics, Department of European Integration Sokolská trída 33, 70121 Ostrava

Email:lukas.melecky@vsb.cz. 


\section{Appendices}

\begin{tabular}{|l} 
Tab. 1 - Indicators of Inputs in Period 2000-2005-2010 Relevant to Factor Analysis. \\
Note: * Number of indicators was decreased after correlation from 38 to 23 \\
Source: Annoni, Kozovska, 2010; own calculation and elaboration, 2012
\end{tabular}

Tab. 2 - Indicators of Outputs in Period 2000-2005-2010 Relevant to Factor Analysis.

Note: * Number of indicators was decreased after correlation from 28 to 15

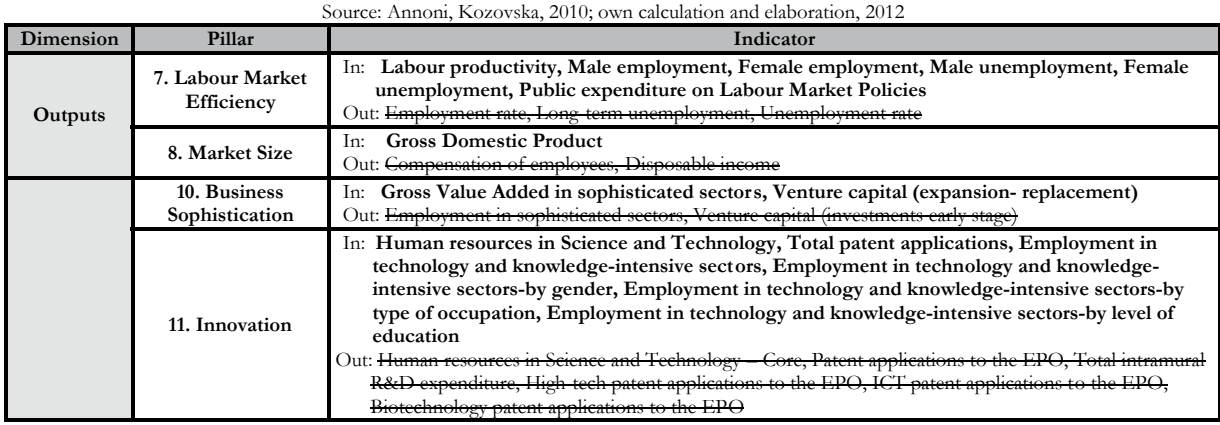


Tab. 3 - Rotated Component Matrix for Inputs in 2000. Source: Own calculation and elaboration, 2012

\begin{tabular}{|c|c|c|c|c|c|}
\hline Year & \multicolumn{5}{|c|}{2000} \\
\hline \multirow[b]{2}{*}{ Component } & \multicolumn{5}{|c|}{ Rotation Sums of Squared Loadings } \\
\hline & Total & \multicolumn{2}{|c|}{$\begin{array}{c}\% \text { of } \\
\text { Variance }\end{array}$} & \multicolumn{2}{|c|}{ Cumulative $\%$} \\
\hline 1 & 7,014 & & 30,497 & & 30,497 \\
\hline 2 & 5,008 & & 21,772 & & 52,269 \\
\hline 3 & 4,638 & & 20,164 & & 72,433 \\
\hline 4 & 4,375 & & 19,022 & & 91,455 \\
\hline \multirow[t]{3}{*}{5} & 1,965 & & 8,545 & & 100,000 \\
\hline & \multicolumn{5}{|c|}{ Component } \\
\hline & 1 & 2 & 3 & 4 & 5 \\
\hline Zscore(HICP) &,- 969 & & & & \\
\hline Zscore(CDDR) &,- 947 & & & & \\
\hline Zscore(SDR) &,- 889 & & & & \\
\hline Zscore(MSTEG) &, 815 & & & & \\
\hline Zscore(GFCF) &, 807 & & & & \\
\hline Zscore(LIA) &, 800 & ,476 & & & \\
\hline Zscore(VFT) &,- 679 & & & & \\
\hline Zscore(AU) &,- 586 & & &, 533 & \\
\hline Zscore(FAS) & & ,968 & & & \\
\hline Zscore(ATP) & ,494 & 823 & & & \\
\hline Zscore(PS) &, 543 &,- 818 & & & \\
\hline Zscore(PTR) &, 496 &, 670 & & & \\
\hline Zscore(TPESLE) & & & ,977 & & \\
\hline Zscore(HDDR) & & &,- 940 & & \\
\hline Zscore(TPETLE) & & &, 822 & & \\
\hline Zscore(ELET) & & ,687 &, 708 & & \\
\hline Zscore(PEE) & & 523 &, 590 & & \\
\hline Zscore(VPT) & & & & ,924 & \\
\hline Zscore(RTLT) & & & & 862 & \\
\hline Zscore(TPEPLE) & &,- 503 & &, 761 & \\
\hline Zscore(PHE) & & & &, 753 & \\
\hline Zscore(HLE) & & & &, 750 &, 544 \\
\hline Zscore(IM) & & & & &,- 873 \\
\hline
\end{tabular}

Tab. 4 -Rotated Component Matrix for Inputs in 2005 Source: Own calculation and elaboration, 2012

\begin{tabular}{|c|c|c|c|c|c|}
\hline Year & \multicolumn{5}{|c|}{2005} \\
\hline \multirow{2}{*}{ Component } & \multicolumn{5}{|c|}{ Rotation Sums of Squared Loadings } \\
\hline & Total & \multicolumn{2}{|c|}{$\%$ of Variance } & \multicolumn{2}{|c|}{ Cumulative $\%$} \\
\hline $\begin{array}{l}1 \\
2 \\
3 \\
4 \\
5\end{array}$ & $\begin{array}{l}6,131 \\
4,880 \\
4,279 \\
3,976 \\
2,735 \\
\end{array}$ & & $\begin{array}{l}27,868 \\
22,180 \\
19,450 \\
18,072 \\
12,431 \\
\end{array}$ & & $\begin{array}{r}27,868 \\
50,047 \\
69,497 \\
87,569 \\
\mathbf{1 0 0 , 0 0 0}\end{array}$ \\
\hline & \multicolumn{5}{|c|}{ Component } \\
\hline & 1 & 2 & 3 & 4 & 5 \\
\hline $\begin{array}{l}\text { Zscore(PHE) } \\
\text { Zscore(PS) } \\
\text { Zscore(AU) } \\
\text { Zscore(HDDR) } \\
\text { Zscore(GFCF) } \\
\text { Zscore(TPEPLE) } \\
\text { Zscore(HLE) } \\
\text { Zscore(PEE) } \\
\text { Zscore(SDR) } \\
\text { Zscore(MSTEG) } \\
\text { Zscore(PTR) } \\
\text { Zscore(TPETLE) } \\
\text { Zscore(FAS) } \\
\text { Zscore(CDDR) } \\
\text { Zscore(VPT) } \\
\text { Zscore(ELET) } \\
\text { Zscore(ATP) } \\
\text { Zscore(LIA) } \\
\text { Zscore(VFT) } \\
\text { Zscore(RTLT) } \\
\text { Zscore(IM) } \\
\text { Zscore(TPESLE) } \\
\text { Zscore(PHE) }\end{array}$ & $\begin{array}{r}, 949 \\
-, 903 \\
, 853 \\
, 820 \\
-, 690 \\
, 674 \\
, 664 \\
-, 655\end{array}$ & $\begin{array}{l}-, 425 \\
-, 545 \\
\\
-, 959 \\
, 944 \\
, 943\end{array}$ & $\begin{array}{l}, 542 \\
, 408 \\
, 409 \\
, 466 \\
-, 403\end{array}$ & $\begin{array}{l}, 939 \\
, 772 \\
, 679 \\
, 660 \\
, 632\end{array}$ & $\begin{array}{r}-, 915 \\
, 654\end{array}$ \\
\hline
\end{tabular}

Tab. 5 -Rotated Component Matrix for Inputs in 2010 Source: Own calculation and elaboration, 2012

\begin{tabular}{|c|c|c|c|c|c|}
\hline Year & \multicolumn{5}{|c|}{2010} \\
\hline \multirow[b]{2}{*}{ Component } & \multicolumn{5}{|c|}{ Rotation Sums of Squared Loadings } \\
\hline & Total & \multicolumn{2}{|c|}{$\begin{array}{c}\% \text { of } \\
\text { Variance }\end{array}$} & \multicolumn{2}{|c|}{ Cumulative $\%$} \\
\hline $\begin{array}{l}1 \\
2 \\
3 \\
4 \\
5 \\
\end{array}$ & $\begin{array}{l}7,0 \\
5,0 \\
4,6 \\
4,3 \\
1,9\end{array}$ & & $\begin{array}{r}30,497 \\
21,772 \\
20,164 \\
19,022 \\
8,545 \\
\end{array}$ & & $\begin{array}{r}30,497 \\
52,269 \\
72,433 \\
91,455 \\
\mathbf{1 0 0 , 0 0 0}\end{array}$ \\
\hline & \multicolumn{5}{|c|}{ Component } \\
\hline & 1 & 2 & 3 & 4 & 5 \\
\hline $\begin{array}{l}\text { Zscore(HICP) } \\
\text { Zscore(CDDR) } \\
\text { Zscore(SDR) } \\
\text { Zscore(MSTEG) } \\
\text { Zscore(GFCF) } \\
\text { Zscore(LIA) } \\
\text { Zscore(VFT) } \\
\text { Zscore(AU) } \\
\text { Zscore(FAS) } \\
\text { Zscore(ATP) } \\
\text { Zscore(PS) } \\
\text { Zscore(PTR) } \\
\text { Zscore(TPESLE) } \\
\text { Zscore(HDDR) } \\
\text { Zscore(TPETLE) } \\
\text { Zscore(ELET) } \\
\text { Zscore(PEE) } \\
\text { Zscore(VPT) } \\
\text { Zscore(RTLT) } \\
\text { Zscore(TPEPLE) } \\
\text { Zscore(PHE) } \\
\text { Zscore(HLE) } \\
\text { Zscore(IM) }\end{array}$ & $\begin{array}{r}, 949 \\
-, 903 \\
, 853 \\
, 820 \\
-, 690 \\
, 674 \\
, 664 \\
-, 655\end{array}$ & $\begin{array}{l}-, 959 \\
, 944 \\
, 943 \\
, 670\end{array}$ & $\begin{array}{r}, 913 \\
-, 866 \\
-, 731 \\
, 697 \\
, 590\end{array}$ & $\begin{array}{l}, 939 \\
, 772 \\
679 \\
660 \\
632 \\
, 939\end{array}$ & $\begin{array}{l}-, 915 \\
, 654\end{array}$ \\
\hline
\end{tabular}

Tab. 6 -Rotated Component Matrix for Outputs in 2000. Source: Own calculation and elaboration, 2012

\begin{tabular}{|c|c|c|c|c|}
\hline Year & \multicolumn{4}{|c|}{2000} \\
\hline \multirow[b]{2}{*}{ Component } & \multicolumn{4}{|c|}{ Rotation Sums of Squared Loadings } \\
\hline & Total & $\begin{array}{c}\% \text { of } \\
\text { Variance }\end{array}$ & \multicolumn{2}{|c|}{ Cumulative $\%$} \\
\hline $\begin{array}{l}1 \\
2 \\
3 \\
4\end{array}$ & $\begin{array}{l}5,091 \\
4,367 \\
2,860 \\
1,958\end{array}$ & $\begin{array}{l}33,938 \\
29,111 \\
19,067 \\
13,052\end{array}$ & & $\begin{array}{l}33,938 \\
63,049 \\
82,116 \\
\mathbf{9 5 , 1 6 8}\end{array}$ \\
\hline & \multicolumn{4}{|c|}{ Component } \\
\hline & 1 & \begin{tabular}{l|l}
2 & \\
\end{tabular} & 3 & 4 \\
\hline $\begin{array}{l}\text { Zscore(FU) } \\
\text { Zscore(MU) } \\
\text { Zscore(EiTaKIS) } \\
\text { Zscore(ETKIgen) } \\
\text { Zscore(ME) } \\
\text { Zscore(LP) } \\
\text { Zscore(GDP) } \\
\text { Zscore(FE) } \\
\text { Zscore(GVA) } \\
\text { Zscore(TPAp) } \\
\text { Zscore(PEoLMP) } \\
\text { Zscore(HRST) } \\
\text { Zscore(VCexp) } \\
\text { Zscore(ETKIocc) } \\
\text { Zscore(ETKIedu) }\end{array}$ & $\begin{array}{r}-, 944 \\
-, 907 \\
, 755 \\
, 731 \\
, 719 \\
, 714 \\
, 659 \\
, 622\end{array}$ & $\begin{array}{l}, 482 \\
, 611 \\
\\
, 988 \\
, 954 \\
, 919 \\
, 817\end{array}$ & $\begin{array}{l}-, 441 \\
-, 506 \\
-, 432 \\
-, 531\end{array}$ & $\begin{array}{l}, 408 \\
, 460\end{array}$ \\
\hline
\end{tabular}


Tab. 7 -Rotated Component Matrix for Outputs in 2005. Source: Own calculation and elaboration, 2012

\begin{tabular}{|c|c|c|c|c|}
\hline Year & \multicolumn{4}{|c|}{2005} \\
\hline \multirow[b]{2}{*}{ Component } & \multicolumn{4}{|c|}{ Rotation Sums of Squared Loadings } \\
\hline & Total & $\begin{array}{r}\% \text { of } \\
\text { Variane }\end{array}$ & Cun & tive $\%$ \\
\hline $\begin{array}{l}1 \\
2 \\
3 \\
4\end{array}$ & $\begin{array}{l}4,991 \\
4,232 \\
4,221 \\
1,340\end{array}$ & $\begin{array}{r}33 \\
28 \\
28 \\
8\end{array}$ & & $\begin{array}{l}33,274 \\
61,485 \\
89,622 \\
\mathbf{9 8 , 5 5 8}\end{array}$ \\
\hline & \multicolumn{4}{|c|}{ Component } \\
\hline & 1 & 2 & 3 & 4 \\
\hline $\begin{array}{l}\text { Zscore(ME) } \\
\text { Zscore(FE) } \\
\text { Zscore(MU) } \\
\text { Zscore(FU) } \\
\text { Zscore(LP) } \\
\text { Zscore(GDP) } \\
\text { Zscore(GVA) } \\
\text { Zscore(TPAp) } \\
\text { Zscore(PEoLMP) } \\
\text { Zscore(HRST) } \\
\text { Zscore(ETKIedu) } \\
\text { Zscore(ETKIocc) } \\
\text { Zscore(EiTaKIS) } \\
\text { Zscore(ETKIgen) } \\
\text { Zscore(VCexp) }\end{array}$ & $\begin{array}{r}, 922 \\
, 882 \\
-, 826 \\
-, 817 \\
, 797 \\
, 769\end{array}$ & $\begin{array}{l}, 555 \\
, 592 \\
, 982 \\
, 936 \\
, 856 \\
, 742\end{array}$ & $\begin{array}{l}, 977 \\
, 959 \\
, 932 \\
, 932\end{array}$ & ,937 \\
\hline
\end{tabular}

Tab. 8 - Rotated Component Matrix for Outputs in 2010. Source: Own calculation and elaboration, 2012

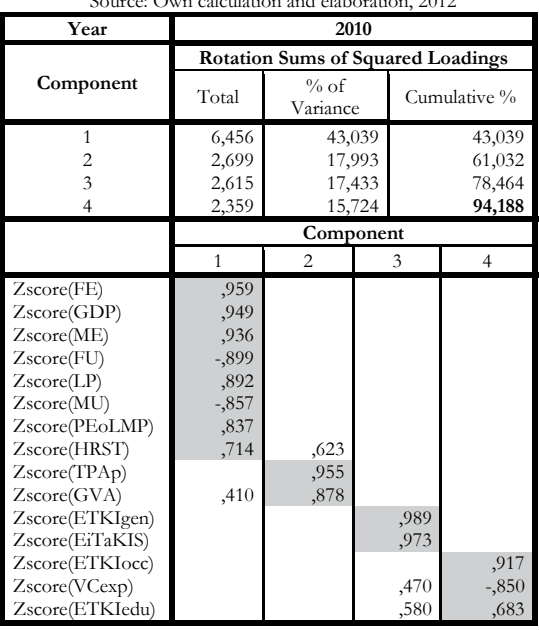

Tab. 9 - Proximity Matrix in 2000.

Source: Own calculation and elaboration, 2012

\begin{tabular}{|l|r|r|r|r|r|r|}
\hline \multirow{2}{*}{ Case } & \multicolumn{7}{|c|}{ Squared Euclidean Distance } \\
\cline { 2 - 7 } & \multicolumn{1}{|c|}{ 1:AT0 } & \multicolumn{1}{|c|}{ 2:CZ0 } & 3:DE0 & 4:HU0 & \multicolumn{1}{|c|}{ 5:PL0 } & \multicolumn{1}{c|}{$6:$ SK0 } \\
\hline 1:AT &, 000 & 47,029 & 64,929 & 89,135 & 100,728 & 77,417 \\
2:CZ & 47,029 &, 000 & 63,323 & 55,327 & 63,377 & 36,711 \\
3:DE & 64,929 & 63,323 &, 000 & 107,928 & 124,983 & 102,638 \\
4:HU & 89,135 & 55,327 & 107,928 &, 000 & 80,359 & 72,218 \\
5:PL & 100,728 & 63,377 & 124,983 & 80,359 &, 000 & 53,896 \\
6:SK & 77,417 & 36,711 & 102,638 & 72,218 & 53,896 &, 000 \\
\hline
\end{tabular}

ab. 10 - Agglomeration Schedule in 2000

Source: Own calculation and elaboration, 2012

\begin{tabular}{|c|c|c|c|c|c|c|}
\hline \multirow{2}{*}{ Stage } & \multicolumn{2}{|c|}{$\begin{array}{c}\text { Cluster } \\
\text { Combined } \\
\end{array}$} & \multirow{2}{*}{ Coefficients } & \multicolumn{2}{|c|}{$\begin{array}{c}\text { Stage Cluster First } \\
\text { Appears }\end{array}$} & \multirow{2}{*}{$\begin{array}{l}\text { Next } \\
\text { Stage }\end{array}$} \\
\hline & $\begin{array}{c}\text { Cluster } \\
1\end{array}$ & $\begin{array}{c}\text { Cluster } \\
2\end{array}$ & & $\begin{array}{c}\text { Cluster } \\
1\end{array}$ & $\begin{array}{c}\text { Cluster } \\
2\end{array}$ & \\
\hline 1 & 2 & 6 & 18,355 & 0 & 0 & 3 \\
\hline 2 & 1 & 3 & 50,820 & 0 & 0 & 5 \\
\hline 3 & 2 & 5 & 83,793 & 1 & 0 & 4 \\
\hline 4 & 2 & 4 & 122,937 & 3 & 0 & 5 \\
\hline 5 & 1 & 2 & 190,000 & 2 & 4 & 0 \\
\hline
\end{tabular}

Tab. 11 - Proximity Matrix in 2005.

Source: Own calculation and elaboration, 2012

\begin{tabular}{|l|r|r|r|r|r|r|}
\hline \multirow{2}{*}{ Case } & \multicolumn{7}{|c|}{ Squared Euclidean Distance } \\
\cline { 2 - 7 } & \multicolumn{1}{|c|}{ 1:AT0 } & 2:CZ0 & 3:DE0 & \multicolumn{1}{c|}{ 4:HU0 } & \multicolumn{1}{|c|}{$5:$ PL0 } & \multicolumn{1}{c|}{$6:$ SK0 } \\
\hline 1:AT &, 000 & 50,162 & 59,870 & 74,726 & 105,336 & 73,082 \\
2:CZ & 50,162 &, 000 & 68,283 & 42,051 & 89,074 & 25,206 \\
3:DE & 59,870 & 68,283 &, 000 & 90,615 & 124,292 & 92,663 \\
4:HU & 74,726 & 42,051 & 90,615 &, 000 & 95,366 & 50,785 \\
5:PL & 105,336 & 89,074 & 124,292 & 95,366 &, 000 & 68,489 \\
6:SK & 73,082 & 25,206 & 92,663 & 50,785 & 68,489 &, 000 \\
\hline
\end{tabular}

Tab. 12 - Agglomeration Schedule in 2005.

Source: Own calculation and elaboration, 2012

\begin{tabular}{|c|c|c|c|c|c|c|}
\hline \multirow{2}{*}{ Stage } & \multicolumn{2}{|c|}{$\begin{array}{c}\text { Cluster } \\
\text { Combined } \\
\end{array}$} & \multirow{2}{*}{ Coefficients } & \multicolumn{2}{|c|}{$\begin{array}{c}\text { Stage Cluster First } \\
\text { Appears }\end{array}$} & \multirow{2}{*}{$\begin{array}{l}\text { Next } \\
\text { Stage }\end{array}$} \\
\hline & $\begin{array}{c}\text { Cluster } \\
1 \\
\end{array}$ & $\begin{array}{c}\text { Cluster } \\
2 \\
\end{array}$ & & $\begin{array}{c}\text { Cluster } \\
1\end{array}$ & $\begin{array}{c}\text { Cluster } \\
2 \\
\end{array}$ & \\
\hline 1 & 2 & 6 & 12,603 & 0 & 0 & 2 \\
\hline 2 & 2 & 4 & 39,347 & 1 & 0 & 4 \\
\hline 3 & 1 & 3 & 69,282 & 0 & 0 & 5 \\
\hline 4 & 2 & 5 & 122,677 & 2 & 0 & 5 \\
\hline 5 & 1 & 2 & 185,000 & 3 & 4 & 0 \\
\hline
\end{tabular}

Tab. 13 - Proximity Matrix in 2010

Source: Own calculation and elaboration, 2012

\begin{tabular}{|l|r|r|r|r|r|r|}
\hline \multirow{2}{*}{ Case } & \multicolumn{7}{|c|}{ Squared Euclidean Distance } \\
\cline { 2 - 7 } & \multicolumn{1}{|c|}{ 1:AT0 } & 2:CZ0 & \multicolumn{1}{c|}{ 3:DE0 } & 4:HU0 & \multicolumn{1}{c|}{ 5:PL0 } & \multicolumn{1}{c|}{$6:$ SK0 } \\
\hline 1:AT &, 000 & 55,283 & 74,692 & 101,908 & 91,834 & 93,371 \\
2:CZ & 55,283 &, 000 & 79,499 & 62,419 & 56,052 & 32,992 \\
3:DE & 74,692 & 79,499 &, 000 & 132,187 & 126,027 & 118,969 \\
4:HU & 101,908 & 62,419 & 132,187 &, 000 & 72,347 & 67,435 \\
5:PL & 91,834 & 56,052 & 126,027 & 72,347 &, 000 & 64,985 \\
6:SK & 93,371 & 32,992 & 118,969 & 67,435 & 64,985 &, 000 \\
\hline
\end{tabular}

Tab. 14 - Agglomeration Schedule in 2010.

Source: Own calculation and elaboration, 2012

\begin{tabular}{|l|r|r|r|r|r|r|}
\hline \multirow{2}{*}{ Stage } & \multicolumn{2}{|c|}{ Cluster Combined } & \multirow{2}{*}{ Coefficients } & \multicolumn{2}{|c|}{$\begin{array}{c}\text { Stage Cluster First } \\
\text { Appears }\end{array}$} & \multirow{2}{*}{$\begin{array}{c}\text { Next } \\
\text { Stage }\end{array}$} \\
\cline { 2 - 3 } & Cluster 1 & Cluster 2 & & $\begin{array}{c}\text { Cluster } \\
1\end{array}$ & $\begin{array}{c}\text { Cluster } \\
\text { Stannn }\end{array}$ \\
\hline 1 & 2 & 6 & 16,496 & 0 & 0 & 2 \\
2 & 2 & 5 & 51,343 & 1 & 0 & 4 \\
3 & 1 & 3 & 88,689 & 0 & 0 & 5 \\
4 & 2 & 4 & 126,404 & 2 & 0 & 5 \\
5 & 1 & 2 & 205,000 & 3 & 4 & 0 \\
\hline
\end{tabular}

